\title{
BMJ Open Diabetes Prevalence Survey of Pakistan (DPS-PAK): prevalence of type 2 diabetes mellitus and prediabetes using HbA1c: a population-based survey from Pakistan
}

\author{
Azizul Hasan Aamir, ${ }^{1}$ Zia Ul-Haq, ${ }^{2,3}$ Saeed A Mahar, ${ }^{4}$ Faisal Masood Qureshi, ${ }^{5}$ \\ Ibrar Ahmad, ${ }^{6}$ Ali Jawa, ${ }^{7}$ Aisha Sheikh, ${ }^{8}$ Abbas Raza, ${ }^{9}$ Sheraz Fazid, ${ }^{2}$ \\ Zahid Jadoon, ${ }^{10}$ Osama Ishtiaq, ${ }^{11}$ Nauman Safdar, ${ }^{12}$ Hussain Afridi, ${ }^{1}$ \\ Adrian $\mathrm{H} \mathrm{Heald}^{13}$
}

To cite: Aamir AH, Ul-Haq Z, Mahar SA, et al. Diabetes Prevalence Survey of Pakistan (DPS-PAK): prevalence of type 2 diabetes mellitus and prediabetes using $\mathrm{HbA} 1 \mathrm{c}$ : a population-based survey from Pakistan. BMJ Open 2019;9:e025300. doi:10.1136/ bmjopen-2018-025300

- Prepublication history for this paper is available online. To view these files, please visit the journal online (http://dx.doi. org/10.1136/bmjopen-2018025300).

Received 14 July 2018 Revised 18 December 2018 Accepted 19 December 2018

Check for updates

(c) Author(s) (or their employer(s)) 2019. Re-use permitted under CC BY-NC. No commercial re-use. See rights and permissions. Published by BMJ.

For numbered affiliations see end of article.

Correspondence to

Professor Azizul Hasan Aamir; drahaamir@gmail.com

\section{ABSTRACT}

Objectives We conducted a Pakistan-wide communitybased survey on the prevalence of type 2 diabetes using glycated haemoglobin $(\mathrm{HbA1c})$ as the screening test. The aim was to estimate diabetes prevalence across different demographic groups as well as all regions of Pakistan.

Design, settings and participants Multistaged stratified cluster sampling was used for the representative selection of people aged $\geq 20$ years, residing in 378 sampled clusters of 16 randomly selected districts, in this crosssectional study. Eligible participants had blood drawn for HbA1c analyses at field clinics near to their homes. The oral glucose tolerance test (OGTT) was conducted on a subsample of the participants. Overall and stratified prevalence of type 2 diabetes and its association with risk factors were estimated using logistic regression models.

Main outcome measures Prevalence of prediabetes and type 2 diabetes.

Results Of 18856 eligible participants the prevalence of prediabetes was $10.91 \%(95 \% \mathrm{Cl} 10.46$ to $11.36, \mathrm{n}=2057)$ and type 2 diabetes was $16.98 \%$ (95\% Cl 16.44 to 17.51 , $\mathrm{n}=3201$ ). Overall, the mean $\mathrm{HbA1c}$ level was $5.62 \%$ (SD 1.96 ), and among newly diagnosed was $8.56 \%$ (SD 2.08). The prevalence was highest in age $51-60$ years $(26.03 \%$, $\mathrm{p}<0.001)$, no formal education $(17.66 \%, \mathrm{p}<0.001)$, class III obese (35.09\%, $p<0.001)$, family history $(31.29 \%$, $p<0.001)$ and female $(17.80 \%, p=0.009)$. On multivariate analysis, there was a significant association between type 2 diabetes and older age, increase in body mass index and central obesity, positive family history, and having hypertension and an inverse relation with education as a categorical variable. $0 n$ a subsample $(n=1027)$, summary statistics for diagnosis of diabetes on $\mathrm{HbA1C}$ showed a sensitivity of $84.7 \%$, specificity of $87.2 \%$ and area under the receiver operating characteristic curve 0.86 , compared with OGTT.

Conclusions The prevalence of type 2 diabetes and prediabetes is much higher than previously thought in Pakistan. Comprehensive strategies need to be developed to incorporate screening, prevention and treatment of type 2 diabetes at a community level.

\section{Strengths and limitations of this study}

Our study has the strength that we carried out glycated haemoglobin $(\mathrm{HbA} 1 \mathrm{c})$ on all participants and oral glucose tolerance test (OGTT) on a subsample.

- Furthermore, this is the largest ever national prevalence study of type 2 diabetes mellitus from Pakistan to date and the first community-based national study to use $\mathrm{HbA1c}$ as the diagnostic tool.

- The relatively low number $(\mathrm{n}=1027)$ of $75 \mathrm{~g}$ 0GTT. Nevertheless, the specificity and sensitivity of $\mathrm{HbA} 1 \mathrm{C}$ versus $0 \mathrm{GTT}$ was good.

- We had to exclude $16 \%$ of recruited participants because of anaemia.

\section{BACKGROUND}

Type 2 diabetes mellitus is one of the most common public health issues worldwide and its incidence is on the rise, particularly in middle-income and low-income countries. ${ }^{1}$ When associated with complications, type 2 diabetes can have a profound impact on the person with consequences also for the society as a whole. Diabetes was previously thought to be a disease of the affluent and mostly prevalent in urban areas but due to urbanisation, change in nutrition and a more sedentary lifestyle for many people, it has affected middle-income and low-income nations, including Pakistan. ${ }^{2}$

Pakistan is a South Asian country with an area of $796095 \mathrm{~km}^{2}$ and a population of 207.7 million people. ${ }^{3}$ In terms of population, Pakistan is the sixth most populous country and is the 36th largest country by geographical area in the world. Before 2018, the only previous national diabetes survey in Pakistan in 1999 (published in 2007), 
reported the prevalence of type 2 diabetes as $11 \%$ using the oral glucose tolerance test (OGTT). ${ }^{45}$ Part of the same survey separately reported the prevalence of type 2 diabetes in different provinces of Pakistan. ${ }^{46-8}$ The International Diabetes Federation (IDF) reported in its Atlas 5 th edition the prevalence for Pakistan to be $6.8 \%$, aged 20-79 years, ${ }^{9}$ but healthcare professionals with local insight always believed this to be an underestimate. Subsequently, there were conflicting findings with prevalence ranging from $7.2 \%$ to $19.21 \%$ in different regions of the country. ${ }^{5}$

The American Diabetes Association (ADA) criteria for the diagnosis of diabetes require either fasting plasma glucose (FPG) or $75 \mathrm{gm}$ OGTT, which is time-consuming, requires fasting and may not always be reproducible. ${ }^{10} 11$ In 2009, the International Expert Committee on diabetes proposed new diagnostic criteria based on glycated haemoglobin (HbA1c), which captures chronic glucose exposure. ${ }^{12}$ The proposed diagnostic threshold of $6.5 \%$ $(48 \mathrm{mmol} / \mathrm{mol}$ ) was based on retinopathy risk at different levels of HbAlc as was the case with FPG and OGTT. This report was followed by a recommendation from the ADA that an HbAlc level of $6.5 \%(48 \mathrm{mmol} / \mathrm{mol})$ be used as the diagnostic cut-off for the diagnoses of diabetes (this has not been validated in Pakistan). ${ }^{13}$

A previous national-level type 2 diabetes survey was conducted in 1999 with a sample size of 5433 using OGTT. In the study described in this paper, we investigated the prevalence of type 2 diabetes (using the HbAlc test) and its distribution across gender, age, rural and urban, education, body mass index (BMI) WHO and Asian cut-offs, family history, smoking and blood pressure among a large sample across Pakistan, aged 20 years and above. A subsample was tested to explore the diagnostic accuracy of HbAlc for diagnosis of type 2 diabetes, compared with the 2-hour OGTT.

\section{METHODS}

The Department of Diabetes, Endocrine and Metabolic Diseases, Hayatabad and Department of Health, Government of Khyber Pakhtunkhwa, Pakistan with technical support from Institute of Public Health, Khyber Medical University Peshawar Pakistan, University of Manchester UK and Pakistan Endocrine Society conducted a nationwide cross-sectional study for the prevalence of type 2 diabetes starting from April 2017 to November 2017. Three teams of trained field workers under the supervision of epidemiologists collected basic demographic data and blood samples from the selected sample. The study sample was selected based on a stratified two-stage cluster design, including all metropolitan cities of Pakistan and randomly selected districts (both rural and urban settings) within each province. The sample included districts from central and south of Punjab province (Lahore, Multan, Bahawalpur, Rahim Yar Khan), interior Sindh (Larkana, Dadoo, Sukkur), central Sindh (Karachi), northern Khyber Pakhtunkhwa (KP) (Haripur), central (Peshawar) and southern KP province (Karak), Baluchistan province (Quetta), capital territory (Rawalpindi-Islamabad), Azad Jammu Kashmir (AJK) (Muzaffarabad), Frontier Region Peshawar and the Khyber Agency in Federal Administered Tribal Area (FATA).

\section{Sample size and sampling methodology}

The sample size was estimated for the provinces of the country based on recent census results. The sample size was estimated based on an expected prevalence of $12 \%$ with $20 \%$ relative precision and a design effect of $2 .{ }^{6}$ For a 95\% CI and an additional adjustment of 32\% for non-responders, keeping in view an exclusion rate due to an expected high prevalence of anaemia, the sample size was 4407 approximated to 4500 in order to have 50 subjects from each cluster. All provinces were included as was the Federal territory. AJK and FATA were considered as one province for the survey purpose because of their small size of the population. The number of eligible subjects was $4500 \times 5=22500$.

Three districts were randomly selected from each province and the sample size was equally divided on these districts. Fifteen hundred subjects (30 clusters, 50 subjects per cluster) were examined in each district. The sample was proportionately divided among urban and rural areas. Probability proportionate to size (PPS) method was used to select clusters from villages in the rural settings of the district. In urban settings, clusters were selected from charges and circles (defined in the national census) using the PPS method.

Maps were obtained from the census office of selected villages/charges/circles $(\mathrm{V} / \mathrm{C} / \mathrm{C})$. Maps of each $\mathrm{V} / \mathrm{C} / \mathrm{C}$ was divided into equal segments such that each segment had approximately 50 persons aged 20 years and above. One segment was randomly selected and every house within the segment was included. All persons aged 20 years and above living in that house were examined until the 50 number was reached. Any person who was absent on the day of survey until evening, was terminally ill, who fitted into exclusion criteria or who refused were marked as non-responders.

Conditions that may affect HbA1c including anaemic subjects with haemoglobin $<120 \mathrm{~g} / \mathrm{L}$ in women and $<140 \mathrm{~g} / \mathrm{L}$ in men, self-reported renal and hepatic dysfunction, recent blood transfusion and use of erythropoietin, age below 20 years or refusal to participate resulted in exclusion. Face-to-face interview was conducted at the participant's home to collect information on demographics (including age, gender, residential area, formal education, family history of diabetes and smoking status) using a paper questionnaire in local languages. Eligible participants were called to a central point established in the hujra (local public gathering place), where their haemoglobin was tested using the Mission Plus Haemoglobin Metre (reflectance photometer technique) (Acon Laboratories, San Diego, USA) (coefficient of variance (CV): $3 \%$ ). Blood pressure was measured using an automated digital blood pressure monitor Konfort Model 
AS-351 in the lying position with the average of three readings was recorded. Weight in kilograms and height in metres was recorded and used to calculate BMI.

Diabetes status was assessed for HbA1c on blood samples using the National Glycohemoglobin Standardisation Programme certified FIA 8000 immunoassay analyser (lateral flow chromatography colloidal gold) traceable to diabetes control and complication trial (DCCT) reference method (CV: 3\%-5\%). To compare the results from HbA1c, 2-hour OGTT was conducted on a random sample of participants from all clusters $(n=1027)$ in the specified standard laboratory using Cobas C311 (Roche Diagnostics, Mannheim, Germany). Participants were given vouchers for free OGTT test within 7 days in a nearby laboratory.

\section{Definitions}

Age was categorised into six groups: 20-30, 31-40, 41-50, 51-60 and 61 and above years. The residential area was classified as urban and rural based on local government criteria. Formal education status was self-reported and was categorised as no formal education, primary, secondary and graduation/postgraduation. BMI was categorised on WHO criteria (1995) into underweight $\left(<18.5 \mathrm{~kg} / \mathrm{m}^{2}\right)$, normal weight $\left(18.5-24.9 \mathrm{~kg} / \mathrm{m}^{2}\right)$, overweight $\left(25-29.9 \mathrm{~kg} / \mathrm{m}^{2}\right)$, class I obese $(30-34.9 \mathrm{~kg}$ / $\left.\mathrm{m}^{2}\right)$, class II obese $\left(35-39.9 \mathrm{~kg} / \mathrm{m}^{2}\right)$ and class III obese $\left(>40 \mathrm{~kg} / \mathrm{m}^{2}\right)$. Waist circumference (WC) was categorised into normal weight (0-93.99), overweight (94-102) and obese (102 and above). Waist-to-hip ratio (WHR) was categorised into normal weight (0-0.89), overweight $(0.90-0.99)$ and obese ( 1 and above). ${ }^{14}$ The family history of diabetes was categorised to negative or positive on the basis of the participant's self-reporting, based on physician's diagnoses. Smoking status was categorised as never, ex or current smoker. Systolic and diastolic blood pressure was measured using a standard procedure and hypertension was defined on a blood pressure measurement of $\geq 140 / 90 \mathrm{~mm} \mathrm{Hg}$ or antihypertensive medication. Patients were considered as known type 2 diabetes based on self-reporting and/or being on dietary or exercise advice, oral antidiabetes medications or insulin. This self-reported group of patients could either be on single medications or on different drug combinations or diet and exercise therapy.

Type 2 diabetes was diagnosed based on HbA1c results in keeping with the WHO levels for non-diabetes $(<5.69 \%$ DCCT aligned $/ 38 \mathrm{mmol} / \mathrm{mol}$ International Federation of Clinical Chemistry (IFFC) units), prediabetes (5.7\%$6.49 \%$ DCCT aligned $/ 39-47 \mathrm{mmol} / \mathrm{mol}$ IFFC units), diabetes $(\geq 6.5 \%$ DCCT aligned $/ 48 \mathrm{mmol} / \mathrm{mol}$ IFFC units). For univariate and multivariate logistic regression models, diabetes was dichotomised to no $(0 ; \mathrm{HbA1c}$ level <6.5) and yes ( 1 ; HbA1c level $\geq 6.5$ ).

\section{Statistical analyses}

Differences in the characteristics of participants by diabetes category were analysed using the $\chi^{2}$ test for categorical data and analysis of variance for continuous data. We examined the association between diabetes and risk factors, that is, age, gender, residence area, education, BMI, family history of diabetes, smoking, systolic and diastolic blood pressure, using univariate and multivariate logistic regression models. Multivariate regression analysis included all these variables.

Taking OGTT as the standard on a subsample, the diagnostic accuracy summary statistics (sensitivity, specificity, area under the receiver operating characteristic (ROC) curve, positive and negative predictive value) for the diagnosis of diabetes using HbAlc were determined. All statistical analyses were performed using Stata V.14 (StataCorp, College Station, Texas, USA). Statistical significance was defined as $\mathrm{p}<0.05$ and analysis were adjusted for the cluster design.

\section{Patient and public involvement statement}

Patients were not involved in the study conception or design. There was consultation with interested representative public bodies but not with individual members of the public.

\section{RESULTS}

Of the 22500 participants, 3644 (16\%) were anaemic and therefore excluded from the study. Out of the remaining, 18856 participants aged 20 years and above were examined from 378 clusters of which 216 were rural generating a response rate of $84 \%$. The mean age was 45.23 years (SD 13.97 years). Most of the participants 10116 (53.55\%) were men, 4148 (21.96\%) were hypertensive and those with higher blood pressure were advised to check their blood pressure by visiting their doctors. Majority of the participants, 13834 (73.24\%), had no formal education and $1209(6.40 \%)$ had graduated; $6010(31.81 \%)$ had a family history of type 2 diabetes. Overall, on WHO cut-off $345(1.83 \%)$ were underweight, 6839 (36.20\%) normal weight, 8038 (42.55\%) overweight, 2864 (15.16\%) class I obese, $633(3.35 \%)$ class II obese and $172(0.91 \%)$ class III obese. On WC cut-off ( $\mathrm{n}=12865), 8574$ (66.64\%) were normal weight, $2318(18.02 \%)$ were overweight and $1974(15.34 \%)$ were obese. On central obesity cut-off (WHR, n=12865), 4271 (33.20\%) were normal weight, $7467(58.04 \%)$ were overweight and $1127(8.76 \%)$ were obese. Mean systolic blood pressure was $126.30 \mathrm{~mm} \mathrm{Hg}$ (SD 14.2) and diastolic blood pressure was $83.24 \mathrm{~mm} \mathrm{Hg}$ (SD 10.2).

Overall, 3201 subjects $(16.98 \%, 95 \%$ CI 16.44 to 17.51) had type 2 diabetes based on HbAlc screening. Prediabetes was present in 2057 subjects $10.91 \%$ (95\% CI 10.46 to 11.36). The mean HbA1c level of the entire cohort $(\mathrm{n}=18856)$ was $5.62 \%$ (SD 1.96), among known type 2 diabetes $(\mathrm{n}=2179)$ had $8.68 \%$ (SD 2.70) and newly diagnosed type 2 diabetes $(n=1577)$ had $8.56 \%$ (SD 2.08). The prevalence of diabetes differed significantly by age, education, BMI, WC, WHR, family history and blood pressure (table 1) (figure 1). The prevalence of diabetes was 
Table 1 Characteristics of the participants by diabetes categories $(n=18856)$

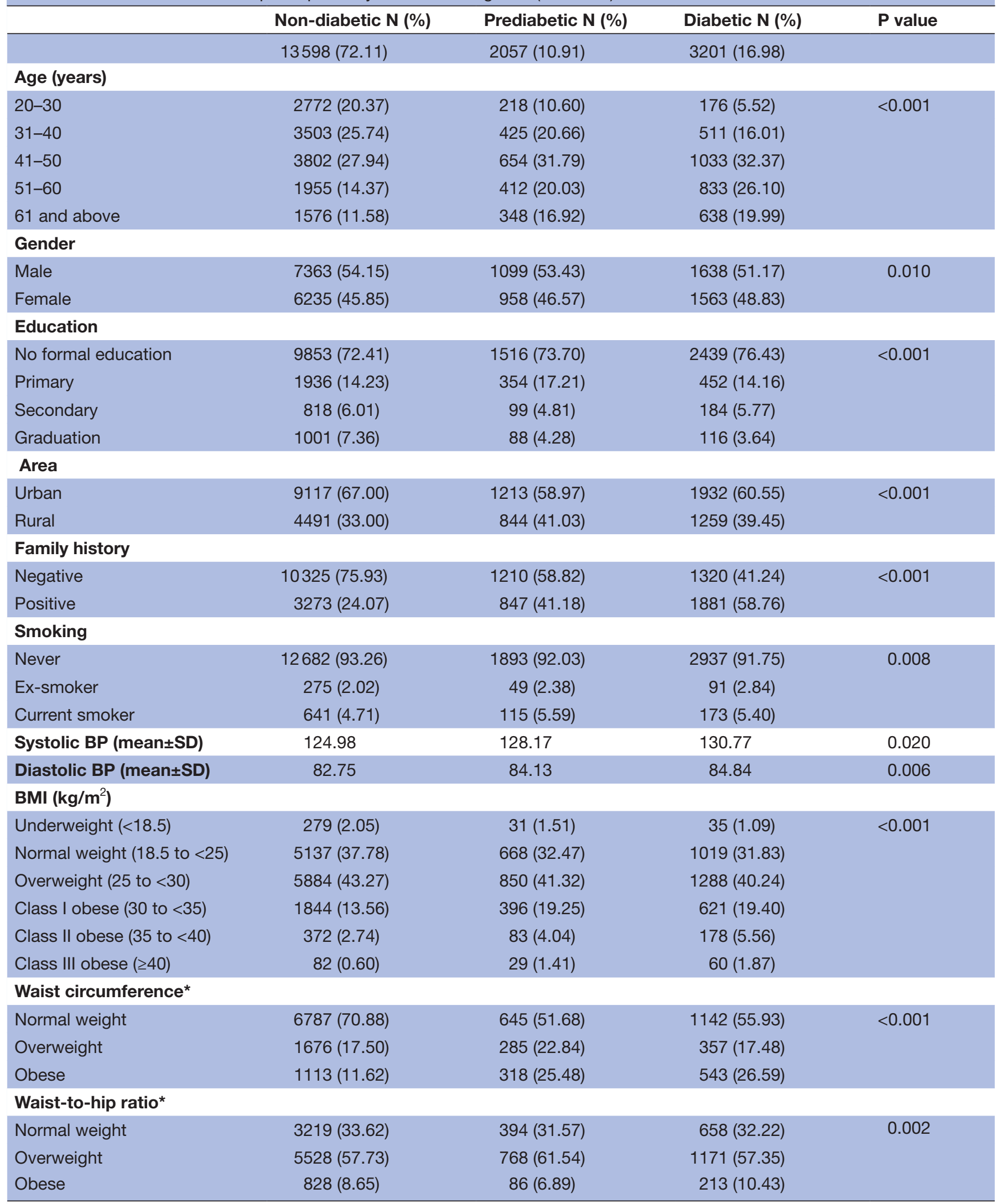

${ }^{*} \mathrm{n}$ for waist circumference and waist-to-hip ratio is 12865 .

$\mathrm{BP}$, blood pressure. 


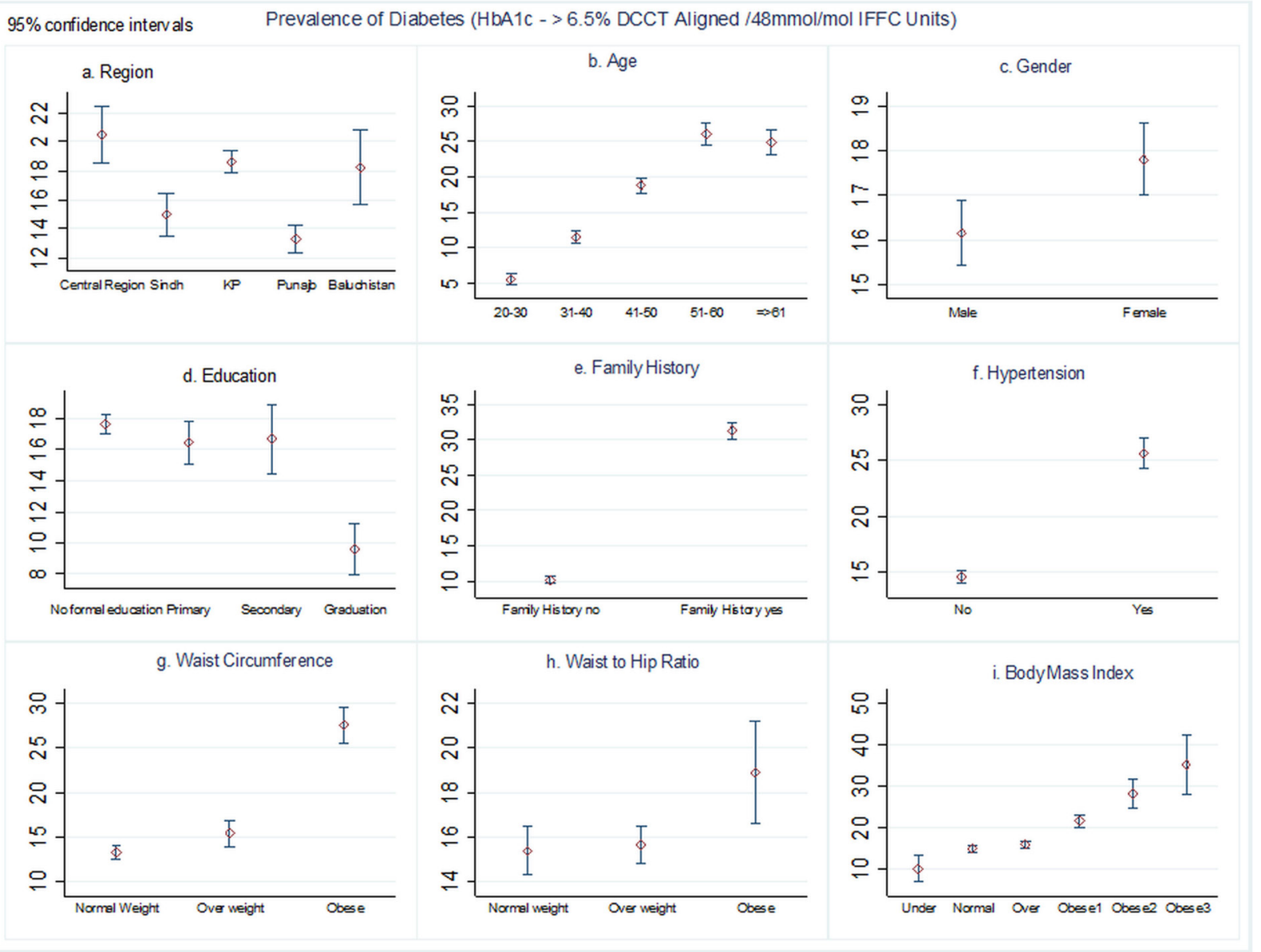

Figure 1 Prevalence of diabetes (diagnosed by glycated haemoglobin $(\mathrm{HbA} 1 \mathrm{c}) \geq 6.5 \%$ diabetes control and complication trial (DCCT) aligned $/ 48 \mathrm{mmol} / \mathrm{mol}$ IFFC units) by regions of Pakistan, age, gender, education, family history of diabetes, hypertension, waist circumference, waist-to-hip ratio and body mass index $(n=18856)$. KP, Khyber Pakhtunkhwa.

highest in age $51-60$ years $(26.03 \%, \mathrm{p}<0.001)$, no formal education $(17.73 \%, \mathrm{p}<0.001)$, class III obese $(32.19 \%$, $\mathrm{p}<0.001)$ and with a positive family history of diabetes $(31.34 \%, \mathrm{p}<0.001)$ (figure 1$)$. There were also statistically significant differences in diabetes prevalence by gender (female $17.85 \%, \mathrm{p}=0.01$ ), rural/urban (rural 19.09\%, $\mathrm{p}<0.001)$ and smoking status $(\mathrm{p}=0.008)$.

On univariate logistic regression analysis, there was a significant association between age, gender, education, BMI category, family history, blood pressure and type 2 diabetes $(\mathrm{p}<0.005)$ (table 2$)$.

On multivariate logistic regression, there was significantly higher risk of diabetes with age (adjusted OR 2.03, $95 \%$ CI 3.39 to 4.87 and $4.93, \mathrm{p}<0.001$, aged $31-40,41-50$, 51-60 and 61 years and above, respectively, compared with aged 20-30 years), BMI (adjusted OR 1.54, 95\% CI 2.13 to $2.44, \mathrm{p}<0.001$ for class I, class II and class III obese, respectively, compared with normal weight) with evidence of a dose-response relationship. Similarly, there was a significantly higher risk of diabetes with lower educational attainment (adjusted OR 1.83, 95\% CI 1.39 to 1.57 , no formal education, primary and secondary education, respectively, compared with graduates). There was a significantly higher risk of diabetes in people with a positive family history (adjusted OR 3.94, 95\% CI 3.6 to $4.3, \mathrm{p}<0.001)$, than with no family history of diabetes. There was no significant association with smoking and rural/urban area.

Among 1029 participants who were tested for 2-hour OGTT, in addition to HbAlc, the mean 2-hour OGTT was 200.26 (SD 91.7), and the median was 178 (IQR 100). Taking the OGTT as the gold standard, HbA1c recommended cut-off for diabetes showed a sensitivity of $84.7 \%$ (95\% CI 80.8 to 88 ) and specificity of $87.2 \%$ (95\% CI 84.3 to $89.8 \%$ ), area under the ROC 0.86 (95\% CI 0.84 to 0.88 ), positive predictive value $81.9 \%$ (95\% CI 77.9 to 85.4 ) and negative predictive value 89.3 (95\% CI 86.5 to 91.6) (table 3).

\section{DISCUSSION}

This is the first community-based national study done in the region based on $\mathrm{HbAlc}$ and with the eligible 18856 subjects from that country makes this as the largest study to date from Pakistan. The prevalence of type 2 diabetes across Pakistan was 16.98\% (95\% CI 16.44 to 17.51) and prediabetes was $10.91 \%$ (95\% CI 10.46 to 11.36 ). This is 
Table 2 Logistic regression analysis of the participant characteristics associated with having diabetes (HbA1c $\geq 6.5 \%$ DCCT aligned $/ 48 \mathrm{mmol} / \mathrm{mol}$ IFFC units) ( $\mathrm{n}=18856)$

\begin{tabular}{|c|c|c|c|c|}
\hline & Univariate & & Multivariate & \\
\hline & OR $(95 \% \mathrm{Cl})$ & $P$ value & OR $(95 \% \mathrm{Cl})$ & $P$ value \\
\hline Age (years) & & & & \\
\hline 20-30 & 1 & & 1 & \\
\hline $31-40$ & 2.21 (1.8 to 2.6$)$ & $<0.001$ & 2.03 (1.7 to 2.4 ) & $<0.001$ \\
\hline $41-50$ & 3.93 (3.3 to 4.6$)$ & $<0.001$ & 3.39 (2.9 to 4.0$)$ & $<0.001$ \\
\hline $51-60$ & 5.97 (5.0 to 7.1$)$ & $<0.001$ & 4.87 (4.1 to 5.8$)$ & $<0.001$ \\
\hline 61 and above & 5.63 (4.7 to 6.7$)$ & $<0.001$ & 4.93 (4.1 to 6.0$)$ & $<0.001$ \\
\hline Gender & & & & \\
\hline Male & 1 & & 1 & \\
\hline Female & 1.12 (1.0 to 1.2$)$ & 0.003 & 1.04 (0.9 to 1.1$)$ & 0.334 \\
\hline Education & & & & \\
\hline No formal education & 2.02 (1.6 to 2.4 ) & $<0.001$ & 1.83 (1.5 to 2.3 ) & $<0.001$ \\
\hline Primary & 1.85 (1.49 to 2.3 ) & $<0.001$ & 1.39 (1.1 to 1.8$)$ & 0.006 \\
\hline Secondary & 1.89 (1.47 to 2.4$)$ & $<0.001$ & 1.57 (1.2 to 2.0$)$ & 0.001 \\
\hline Graduation & 1 & & 1 & \\
\hline Area & & & & \\
\hline Urban & 1 & & 1 & \\
\hline Rural & 1.26 (1.16 to 1.34$)$ & $<0.001$ & 1.08 (0.9 to 1.2$)$ & 0.084 \\
\hline Family history & & & & \\
\hline Negative & 1 & & 1 & \\
\hline Positive & 3.98 (3.6 to 4.3 ) & $<0.001$ & 3.94 (3.6 to 4.3 ) & $<0.001$ \\
\hline Smoking & & & & \\
\hline Never & 1 & & 1 & \\
\hline Ex-smoker & 1.39 (1.1 to 1.8$)$ & 0.006 & 1.13 (0.9 to 1.5$)$ & 0.323 \\
\hline Current smoker & 1.13 (0.9 to 1.3 ) & 0.14 & 1.06 (0.9 to 1.3$)$ & 0.571 \\
\hline Systolic BP & $1.02(1.021$ to 1.026$)$ & $<0.001$ & 1.01 (1.01 to 1.02$)$ & $<0.001$ \\
\hline Diastolic BP & 1.01 (1.01 to 1.02$)$ & $<0.001$ & 0.99 (0.9 to 1.0$)$ & 0.310 \\
\hline BMI $\left(\mathrm{kg} / \mathrm{m}^{2}\right)$ & & & & \\
\hline Underweight $(<18.5)$ & 0.64 (0.4 to 0.9$)$ & 0.001 & 0.71 (0.5 to 1.0$)$ & 0.077 \\
\hline Normal weight $(18.5$ to $<25)$ & 1 & & 1 & \\
\hline Overweight $(25$ to $<30)$ & 1.08 (0.9 to 1.2$)$ & 0.06 & 1.06 (0.9 to 1.1$)$ & 0.182 \\
\hline Class I obese $(30$ to $<35)$ & 1.57 (1.4 to 1.7$)$ & $<0.001$ & 1.54 (1.3 to 1.7$)$ & $<0.001$ \\
\hline Class II obese $(35$ to $<40)$ & 2.22 (1.8 to 2.6$)$ & $<0.001$ & 2.13 (1.7 to 2.6$)$ & $<0.001$ \\
\hline Class III obese $(\geq 40)$ & 3.07 (2.2 to 4.2$)$ & $<0.001$ & 2.44 (1.7 to 3.5$)$ & $<0.001$ \\
\hline WC* & & & & \\
\hline Normal weight & 1 & & 1 & \\
\hline Overweight & 1.18 (1.04 to 1.34$)$ & 0.01 & 0.98 (0.8 to 1.1$)$ & 0.774 \\
\hline Obese & 2.46 (2.19 to 2.77 ) & $<0.001$ & 1.86 (1.6 to 2.2 ) & $<0.001$ \\
\hline WHR $^{*}$ & & & & \\
\hline Normal weight & 1 & & 1 & \\
\hline Overweight & 1.02 (0.92 to 1.13$)$ & 0.40 & 0.8 (0.7 to 0.9$)$ & $<0.001$ \\
\hline Obese & 1.27 (1.07 to 1.51$)$ & 0.005 & 1.13 (0.9 to 1.4$)$ & 0.205 \\
\hline
\end{tabular}

${ }^{*} n$ for WC and WHR is 12865 . The following variables were included in the multivariate regression: age, gender, education, residence area, family history of diabetes, smoking, systolic BP and diastolic BP and BMI.

BMI, body mass index; BP, blood pressure; DCCT, diabetes control and complication trial; HbA1c, glycated haemoglobin; WC, waist circumference; WHR, waist-to-hip ratio. 
Table 3 Summary statistics for diabetes diagnosed by HbA1c compared with diabetes diagnosed by 2-hour OGTT ( $\mathrm{n}=1027)$

$95 \% \mathrm{Cl}$

\begin{tabular}{llccc}
\hline Prevalence & $\operatorname{Pr}(\mathrm{A})$ & $40.6 \%$ & 37.6 & 43.7 \\
Sensitivity & $\operatorname{Pr}(+\mid \mathrm{A})$ & $84.7 \%$ & 80.8 & 88.0 \\
Specificity & $\operatorname{Pr}(-\mid \mathrm{N})$ & $87.2 \%$ & 84.3 & 89.8 \\
Area under the ROC & $(\mathrm{Sens} .+\mathrm{Spec}) / 2$. & 0.86 & 0.84 & 0.88 \\
Likelihood ratio $(+)$ & $\operatorname{Pr}(+\mid \mathrm{A}) / \operatorname{Pr}(+\mid \mathrm{N})$ & 6.62 & 5.36 & 8.18 \\
Likelihood ratio $(-)$ & $\operatorname{Pr}(-\mid \mathrm{A}) / \operatorname{Pr}(-\mid \mathrm{N})$ & 0.18 & 0.14 & 0.22 \\
OR & $\operatorname{LR}(+) / \mathrm{LR}(-)$ & 37.62 & 26.34 & 53.73 \\
$\begin{array}{l}\text { Positive predictive value } \\
\text { Negative predictive }\end{array}$ & $\operatorname{Pr}(\mathrm{A} \mid+)$ & $81.9 \%$ & 77.9 & 85.4 \\
value & $\operatorname{Pr} \mid-)$ & $89.3 \%$ & 86.5 & 91.6 \\
\hline
\end{tabular}

HbA1c, glycated haemoglobin; OGT, oral glucose tolerance test; ROC, receiver operating characteristic.

higher than found in the only previous national survey conducted in1999 ( $\mathrm{n}=5433)$ using OGTT. There was a significantly higher risk of type 2 diabetes with increasing systolic blood pressure, age, BMI, WC, WHR with evidence of a dose-response relationship. Similarly, there was a significant inverse relationship of type 2 diabetes with the level of formal education. The risk of diabetes increased 2.68 times with a prior family history. The HbAlc level had good sensitivity and specificity level for the diagnosis of type 2 diabetes compared with a 2-hour OGTT level and is therefore valid in community settings for screening purposes.

We have noted the findings of Basit et al. ${ }^{15}$ The methodology for that recently published study was based on $75 \mathrm{~g}$ OGTT for glucose handling as opposed to HbAlc used in our study. While the prevalence of diabetes and prediabetes is different in the two studies, the point that both studies make is that both diabetes and prediabetes are much more prevalent than previously thought.

The previous national prevalence study conducted in 1999 used OGTT where almost $80 \%$ of the subjects were women as the test was conducted in the morning time. ${ }^{4}$ In contrast, our study screening was done all through the day so that working men had an equal opportunity to be part of the study. They constituted 50\% of the study population. OGTT is the gold standard for the type 2 diabetes screening but because of the length of time which is required for the test and the fact that the person must be fasting, it is very difficult to perform in many community settings in Pakistan. Also, the high temperatures in South Asia make it difficult to keep the sample stable for transportation to the laboratory. To minimise the effect of temperature and transportation errors on $\mathrm{HbAlc}$, all tests were conducted in the field.

Recently, a study carried out in 15 states of India showed that the prevalence of type 2 diabetes ranged between $4 \%$ and $13.6 \%$ and showed variation due to age, male sex, obesity and family history using capillary fasting blood glucose (FBG) for diagnosis. ${ }^{16}$ A capillary blood sample for epidemiological studies is not an ideal test but the authors acknowledged the logistic hindrance in carrying out venous sample test in the field. A high prevalence in another Indian study was reported ranging from $12.1 \%$ to $14 \%$ for diabetes using OGTT on a sample size of 11216 subjects. ${ }^{17}$

A study conducted in Bangladesh based on capillary fasting level found a prevalence of type 2 diabetes of $4.3 \%$ in a rural setting. ${ }^{18}$ Risk factors were positive family history for diabetes, age, high BMI and low socioeconomic status, similar to our study. Although these are geographically distant areas, the risk factors showed commonality in both studies, which suggests these risk factors as an important tool for mass screening. ${ }^{19}$

The age-standardised and sex-standardised prevalence of type 2 diabetes for Sri Lankans was $10.3 \%$ based on OGTT. ${ }^{20}$ The risk factors were almost the same as seen in our study. The investigators found dysglycaemia in almost $21.8 \%$ participants and predicted that this would lead to a higher prevalence of type 2 diabetes mellitus in the years to come. Another study from Sri Lanka indicated a prevalence of $14.2 \%$ basis of $\mathrm{FBG}^{21}{ }^{21} \mathrm{FBG}$ as well as, OGTT blood glucose levels, may not be reproducible in an epidemiological survey if the individual are changing lifestyle in terms of diet and exercise. The use of HbAlc in our study makes our study more scientific, addressing issues pertaining to sampling errors in the local environment.

The Asian population is known to have a significantly higher risk of developing diabetes and its related complications as predicted by IDF projections. ${ }^{1}$ It makes it very important from a public health point of view to identify high-risk individuals at an early stage. The HbA1c test has been used successfully in community settings. ${ }^{22}$ A national health survey in New Zealand in 2008-2009 used HbA1c to identify high-risk individuals with diabetes and prediabetes. ${ }^{23}$ A study in Japan revealed that a combination of tests including FBG and HbAlc yields more diabetes cases compared with any of these tests alone. ${ }^{24}$

WHO experts have accepted HbA1c as a diagnostic tool provided quality assurance tests are in place and there are no conditions present, which preclude its accurate 
measurement. The New Zealand Society for the study of diabetes and the Australian Diabetes Society have already endorsed $\mathrm{HbAlc}$ as a test for the diagnosis of diabetes. ${ }^{25}{ }^{26}$ Recently, a prevalence study done in Korea concluded that FBG testing results in underestimation of diabetes and prediabetes. ${ }^{27}$ This study suggested the use of standardised HbA1c as a diagnostic tool for diagnosis of type 2 diabetes.

We found that HbA1c had a good sensitivity and specificity level for diagnoses of diabetes compared with the OGTT. HbAlc has the advantage of being a simple test and less time-consuming, making it an ideal test for community surveys in our populations. In Pakistan, as there is no effective primary care (general/family practice) structure most of the population does not undergo primary screening for diabetes. Sometimes as the diagnosis is not made, people may present to tertiary care with complications.

Thus, there is a strong case for applying HbAlc for screening purposes in the community setting. There will always be an argument about the cost of the test and whether this to be used for screening purposes. However, particularly those at social disadvantage need to undergo screening to improve the diagnosis and timely treatment of diabetes. ${ }^{28}$ Early diagnosis will also reduce diabetes-related complications.

\section{Strengths and limitations}

Our study has the strength that we carried out HbAlc on all participants and OGTT on a subsample. Furthermore, this is the largest ever national prevalence study of type 2 diabetes mellitus from Pakistan and the first community-based national study to use HbAlc as the diagnostic tool.

Limitations are the relatively low number $(n=1027)$ of $75 \mathrm{~g}$ OGTT. Nevertheless, the specificity and sensitivity of HbA1c versus OGTT was good. We had to exclude $16 \%$ of recruited participants because of anaemia.

The central Government of Pakistan developed and agreed on non-communicable diseases (NCD) National Action Plan including diabetes; however, it was never implemented. After the 18th Amendment in the constitution of Pakistan in 2010, provinces are responsible for making and implementing their own health policies and the role of central Government is limited to coordination among the different provinces. ${ }^{29}$ There is a dire need that based on the agreed NCD National Action Plan each province should build their capacity for implementing it at both primary and secondary level. Pakistan is a signatory to the Sustainable Development Goals 2030 document, which outlines among its goals, increasing access to universal health coverage, increasing coverage of health insurance programme and adopting a family medicine approach. When implemented, these will be major steps towards prevention and control of diabetes and all NCD.

\section{CONCLUSIONS}

This national diabetes prevalence study is the first one in the region using HbA1c identified a huge population of type 2 diabetes and prediabetes group. The prevalence of type 2 diabetes and prediabetes is much higher than previously thought in Pakistan. Comprehensive strategies need to be developed to incorporate screening, prevention and treatment of type 2 diabetes at community level. Those who are obese, with no formal education, older, family history of diabetes and hypertensive merit close attention and timely intervention.

HbAlc is an applicable test in community settings in middle-income and low-income countries and it has a good correlation with 2-hour OGTT. Our findings have the potential to influence policy in middle-income and low-income countries and induce a shift towards the prevention and control of NCD.

\section{Author affiliations}

${ }^{1}$ Department of Diabetes, Endocrinology and Metabolic Diseases, Hayatabad Medical Complex, Peshawar, Pakistan

${ }^{2}$ Institute of Public Health \& Social Sciences, Khyber Medical University, Peshawar, Pakistan

${ }^{3}$ Institute of Health and Wellbeing, University of Glasgow, Glasgow, UK ${ }^{4}$ Endocrinology, National Institute of Cardiovascular Diseases, Karachi, Pakistan

${ }^{5}$ Endocrinology, Al-Khaliq Hospital, Multan, Multan, Punjab, Pakistan

${ }^{6}$ Endocrinology Ward, Lady Reading Hospital, Peshawar, Pakistan

${ }^{7}$ Endocrinology, Pakistan Institute of Medical Sciences, Islamabad, Pakistan

${ }^{8}$ Endocrinology, Aga Khan University, Karachi, Pakistan

${ }^{9}$ Endocrinolgy, Shaukat Khanum Memorial Cancer Hospital and Research Centre, Lahore, Pakistan

${ }^{10}$ Hayatabad Medical Complex Department of Ophthalmology, Epidemiology,

Peshawar, KP, Pakistan

${ }^{11}$ Endocrinology, Shifa College of Medicine, Islamabad, Pakistan

${ }^{12}$ Social Work, Social and Health Inequalities Network, Islamabad, Islamabad, Pakistan

${ }^{13}$ The School of Medicine and Manchester Academic Sciences Centre, University of Manchester, Manchester, UK

Acknowledgements The authors would like to thank Khyber Pakhtunkhwa Government of Pakistan and field staff for supporting the survey, the Pakistan Endocrine Society for technical and logistic support. The authors would also like to thank The Institute of Public Health, Professor Dr Zia and his team particularly Dr Basharat Hussain Shah at Khyber Medical University for statistical support and the University of Manchester for help in data analysis and in reviewing the manuscript.

Contributors AHA, ZU-H conceived the study. AHA, SM, FQ, AS, AJ, OI, AR, IA, HA collected the data. ZJ, NS studied design and data monitoring. ZUH, AHA, SF, $\mathrm{AH}$ conducted the analysis and wrote the manuscript. All authors reviewed the manuscript. AHA and ZU-H contributed equally.

Funding The authors have not declared a specific grant for this research from any funding agency in the public, commercial or not-for-profit sectors.

Competing interests None declared.

Patient consent for publication Not required.

Ethics approval The ethical approval was granted from the Khyber Medical University ethical board (DIR/KMU-EB/SP/000395).

Provenance and peer review Not commissioned; externally peer reviewed.

Data sharing statement Data generated by our research that supports our article will be made available as soon as possible.

Open access This is an open access article distributed in accordance with the Creative Commons Attribution Non Commercial (CC BY-NC 4.0) license, which permits others to distribute, remix, adapt, build upon this work non-commercially, and license their derivative works on different terms, provided the original work is 
properly cited, appropriate credit is given, any changes made indicated, and the use is non-commercial. See: http://creativecommons.org/licenses/by-nc/4.0/.

\section{REFERENCES}

1. Cho NH, Shaw JE, Karuranga S, et al. IDF Diabetes Atlas: Global estimates of diabetes prevalence for 2017 and projections for 2045. Diabetes Res Clin Pract 2018;138:271-81.

2. Roglic G, Unwin N, Bennett PH, et al. The burden of mortality attributable to diabetes: realistic estimates for the year 2000. Diabetes Care 2005;28:2130-5.

3. Provisional summary results of 6 th population and housing census-2017. Secondary Provisional summary results of 6th population and housing census-2017. http: //www.pbs.gov.pk/ content/provisional-summary-results-6th-population-and-housingcensus-2017-0 (accessed July 2018).

4. Shera AS, Jawad F, Maqsood A. Prevalence of diabetes in Pakistan. Diabetes Res Clin Pract 2007;76:219-22.

5. Meo SA, Zia I, Bukhari IA, et al. Type 2 diabetes mellitus in Pakistan: current prevalence and future forecast. J Pak Med Assoc 2016;66:1637-42.

6. Shera AS, Rafique G, Khwaja IA, et al. Pakistan National Diabetes Survey prevalence of glucose intolerance and associated factors in North West at Frontier Province (NWFP) of Pakistan. J Pak Med Assoc 1999;49:206-11.

7. Shera AS, Rafique G, Khawaja IA, et al. Pakistan national diabetes survey: prevalence of glucose intolerance and associated factors in Baluchistan province. Diab Res Clin Pract 1999;44:49-58.

8. Shera AS, Rafique G, Khwaja IA, et al. Pakistan national diabetes survey: prevalence of glucose intolerance and associated factors in Shikarpur, Sindh Province. Diabet Med 1995;12:1116-21.

9. Whiting DR, Guariguata L, Weil C, et al. IDF diabetes atlas: global estimates of the prevalence of diabetes for 2011 and 2030. Diabetes Res Clin Pract 2011:94:311-21.

10. American Diabetes Association. Diagnosis and classification of diabetes mellitus. Diabetes Care 2014;37:S81-90.

11. Klein BE. Overview of epidemiologic studies of diabetic retinopathy. Ophthalmic Epidemiol 2007;14:179-83.

12. International Expert Committee. International Expert Committee report on the role of the $\mathrm{A} 1 \mathrm{C}$ assay in the diagnosis of diabetes. Diabetes Care 2009;32:1327-34.

13. American Diabetes Association. Diagnosis and classification of diabetes mellitus. Diabetes Care 2010;33(Suppl 1):S62-9.

14. Ahmad N, Adam SI, Nawi AM, et al. Abdominal obesity indicators: waist circumference or waist-to-hip ratio in malaysian adults population. Int J Prev Med 2016;7:82
15. Basit A, Fawwad A, Qureshi H, et al. Prevalence of diabetes, prediabetes and associated risk factors: second National Diabetes Survey of Pakistan (NDSP), 2016-2017. BMJ Open 2018:8:e020961.

16. Anjana RM, Deepa M, Pradeepa R, et al. Prevalence of diabetes and prediabetes in 15 states of India: results from the ICMR-INDIAB population-based cross-sectional study. Lancet Diabetes Endocrinol 2017:5:585-96.

17. Ramachandran A, Snehalatha C, Kapur A, et al. High prevalence of diabetes and impaired glucose tolerance in India: National Urban Diabetes Survey. Diabetologia 2001;44:1094-101.

18. Sayeed MA, Mahtab H, Akter Khanam P, et al. Diabetes and impaired fasting glycemia in a rural population of Bangladesh. Diabetes Care 2003;26:1034-9.

19. McKeigue PM, Marmot MG, Syndercombe Court YD, et al. Diabetes hyperinsulinaemia, and coronary risk factors in Bangladeshis in east London. Br Heart J 1988;60:390-6.

20. Katulanda P, Constantine GR, Mahesh JG, et al. Prevalence and projections of diabetes and pre-diabetes in adults in Sri Lanka-Sri Lanka Diabetes, Cardiovascular Study (SLDCS). Diabet Med 2008;25:1062-9.

21. Wijewardene K, Mohideen MR, Mendis S, et al. Prevalence of hypertension, diabetes and obesity: baseline findings of a population based survey in four provinces in Sri Lanka. Ceylon Med $J$ 2005;50:62-70.

22. Grant T, Soriano Y, Marantz PR, et al. Community-based screening for cardiovascular disease and diabetes using HbA1c. Am J Prev Med 2004;26:271-5.

23. Coppell KJ, Mann JI, Williams SM, et al. Prevalence of diagnosed and undiagnosed diabetes and prediabetes in New Zealand: findings from the 2008/09 Adult Nutrition Survey. N Z Med J 2013;126:23-42.

24. Takahashi $Y$, Noda M, Tsugane S, et al. Prevalence of diabetes estimated by plasma glucose criteria combined with standardized measurement of $\mathrm{HbA} 1 \mathrm{c}$ among health checkup participants on Miyako Island, Japan. Diabetes Care 2000;23:1092-6.

25. d'Emden MC, Shaw JE, Colman PG, et al. The role of HbA1c in the diagnosis of diabetes mellitus in Australia. Med J Aust 2012;197:220-1.

26. Braatvedt GD, Cundy T, Crooke M, et al. Understanding the new $\mathrm{HbA1c}$ units for the diagnosis of Type 2 diabetes. $N Z \mathrm{Med} J$ 2012;125:70-80.

27. Jeon JY, Ko S-H, Kwon H-S, et al. Prevalence of Diabetes and Prediabetes according to Fasting Plasma Glucose and HbA1c. Diabetes Metab J 2013;37:349-57.

28. Degeling C, Rock M, Rogers WA. Testing relationships: ethical arguments for screening for type 2 diabetes mellitus with $\mathrm{HbA1C} . J$ Med Ethics 2012;38:180-3.

29. Nishtar S, Boerma T, Amjad S, et al. Pakistan's health system: performance and prospects after the 18th Constitutional Amendment. Lancet 2013;381:2193-206. 